\title{
Role of Intravenous Tranexamic Acid before Elective Caesarean Section in Preventing Postpartum Hemorrhage
}

\author{
Sadaf Naeemㄴ, Memona Shaukat², Ammara Niaz³ ${ }^{3}$ Tasnim Tahira4 ${ }^{4}$ Amna Batool ${ }^{5}$, Sehrish Maqsood ${ }^{6}$ \\ 1,5,6Department of Gynecology \& Obstetrics, Allied Hospital, Faisalabad-Pakistan, ${ }^{2}$ Consultant Gynecologist, Faisalabad-Pakistan 3,4Department of Gynecology \& Obstetrics, Faisalabad \\ Medical University, Faisalabad-Pakistan
}

\begin{abstract}
Background: Post-partum hemorrhage is one of the most common obstetric emergencies. However, Tranexamic acid (TXA) is a medication used to treat or prevent excessive blood loss due to trauma, surgery and medical conditions including hemophilia and heavy menstrual bleeding. Objective: To determine the role of intravenous tranexamic acid before elective caesarean section in preventing postpartum hemorrhage at tertiary care hospital. Study Design: Randomized control trial. Settings: Obstetrics \& Gynecology Department, Allied Hospital Faisalabad Pakistan. Duration: 6 months from March 02, 2019 to August 01, 2019. Methodology: After taking demographic information and informed consent, all the patients were randomly divided into two groups by using random number table. Group A patients received tranexamic acid ( $1 \mathrm{gm} / 10 \mathrm{ml}$ TA diluted with $20 \mathrm{ml}$ of $5 \% \mathrm{glucose})$ and group B patients not received tranexamic acid (placebo). Blood loss was noted by measuring the total blood collected in kidney tray of 10 " size during delivery of placenta till completion of caesarean section. All this information was recorded through study proforma. Data was entered and analyzed on SPSS version 21. Results: In our study the mean age of the patients was $29.90 \pm 6.06$ years. The mean blood loss value of the patients was $387.27 \pm 89.56 \mathrm{ml}$. Statistically highly significant difference was found between the study groups with blood loss of the patients i.e. $p$-value $=0.000$. Conclusion: It has been proved in our study that the tranexamic acid is useful and effective drug to control the mean blood loss before delivery in females undergoing elective caesarean section as compared to placebo group.
\end{abstract}

Keywords: Caesarean section, Placebo, Tranexamic acid, Blood loss.

Corresponding Author

Submitted for Publication: 13-12-2019

Dr. Sadaf Naeem, Senior Registrar, Gynecology \& Obstetrics, Allied Hospital, Faisalabad-Pakistan.

Email: dr.sadafnaeem@gmail.com

Citation: Naeem S, Shaukat M, Niaz A, Tahira T, Batool A, Maqsood S. Role of Intravenous Tranexamic Acid before Elective Caesarean Section in Preventing Postpartum Hemorrhage. APMC 2020;14(3):245-8.

\section{DOI: $10.29054 / A P M C / 2020.599$}

\section{INTRODUCTION}

Post-partum hemorrhage is one of the most common obstetric emergency. It remains a leading cause of early maternal death accounting for about 300,000 deaths worldwide every year and of morbidity related to anemia, blood transfusions and hemorrhage related ischemic complications. ${ }^{1}$ The incidence of caesarean delivery is increasing day by day and the average blood loss during caesarean delivery $(1000 \mathrm{ml})$ is double the amount lost during vaginal delivery $(500 \mathrm{ml}){ }^{2}$

In Pakistan, the caesarean section rate is $25 \% .^{3}$ The hematocrit falls by $10 \%$ and blood transfusion is required in $6 \%$ of patients undergoing caesarean delivery. ${ }^{3}$ Thus obstetric hemorrhage during caesarean section can be life threatening. To reduce morbidity and mortality associated with obstetric hemorrhage various pharmaceutical, hematological and surgical techniques have been used to prevent PPH during caesarean section. Medications such as oxytocin, misoprostol, prostaglandins $\mathrm{F} 2 \mathrm{a}$ and methysergide have been used to control bleeding after caesarean section. ${ }^{4}$

Tranexamic acid, a synthetic derivative of amino acid Lysine, is an antifibrinolytic that reversibly inhibits the activation of plasminogen thus inhibits fibrinolysis and reduces bleeding. This hemostatic drug is included in WHO list of essential medicines. ${ }^{5}$ It has been used for various types of intra-operative and post-operative bleeding in Gynecology and Obstetrics, tranexamic acid has already been used to treat idiopathic menorrhagia and is effective and well tolerated when administrated orally. ${ }^{6}$ Tranexamic acid can be used in addition to current prophylactic uterotonic drugs in the third stage of labour to reduce blood loss. ${ }^{7}$ Some randomized controlled studies have shown that TXA reduces post-partum hemorrhage during caesarean section. The mean estimated blood loss was significantly lower in women treated with TXA compared with women in the other group in which only standard routine uterotonic drugs were used $(499.9 \pm 206.4 \mathrm{ml}$ versus $600.7 \pm 215.7 \mathrm{ml}$ respectively; $p<0.001) .{ }^{2}$ Another trial has also showed that Tranexamic acid significantly reduced the quantity of blood loss from placental delivery to the end of LSCS which was $356.44 \pm 143.2 \mathrm{ml}$ in the TXA group versus $710.22 \pm 216.72 \mathrm{ml}$ in the placebo group $(p<0.001) .^{3}$ But in one trial, the mean blood loss was $336.7 \pm 151.2 \mathrm{ml}$ in the TXA group and $368.5 \pm 156.4 \mathrm{ml}$ in the control group. However, the amount of blood loss in the period from placental delivery to the end of CS did not differ between the TXA and control groups $(p=0.17) .{ }^{8}$ The rationale of this study is to compare mean blood loss with tranexamic acid versus placebo given before delivery in females undergoing elective caesarean section. In literature, controversial results have been observed. It is known that TXA is effective in controlling bleeding in many surgical procedures. 
But its role in prevention of excessive blood loss, when used as prophylactic drug, has contradiction. So, we want to conduct this study to resolve this controversy. If it proves to be effective, we will recommend the use of this safe, cost-effective and easily available pharmacological therapy to prevent excessive blood loss and prevent post-partum hemorrhage and to reduce the morbidity and mortality associated with post-operative blood transfusions. This will help to improve our practice and guidelines for prevention of excessive blood loss and complications associated with excessive blood loss.

The objective of this study is to compare mean blood loss with tranexamic acid versus placebo given before delivery in females undergoing elective caesarean section.

\section{METHODOLOGY}

Study Design: Randomized control trial.

Settings: Obstetrics \& Gynecology Department, Allied Hospital Faisalabad Pakistan.

Duration: 6 months March 02, 2019 to August 01, 2019.

Sample Size: Sample size of 200 cases; 100 cases in each group is calculated with $95 \%$ confidence level, $90 \%$ power of test and taking magnitude of mean blood loss i.e. $499.9 \pm 206.4 \mathrm{ml}$ with tranexamic acid and $600.7 \pm 215.7 \mathrm{ml}$ with placebo in females undergoing elective caesarean section. ${ }^{16}$ Sample Technique: Non-probability, consecutive sampling Inclusion Criteria:

- All elective LSCS due to malpresentation and repeat LSCS in women of age $20-40$ years having parity $<5$

- Singleton pregnancy (confirmed by Ultrasonography)

- Gestational age of $\geq 38$ weeks (confirmed by LMP)

Exclusion Criteria:

- Placenta previa, abruption, Accreta, increta, percereta (on ultrasonography)

- Uterine fibroid, Polyhydramnios (AFI $>24 \mathrm{~cm})$, Fetal macrosomia (on USG)

- Preeclampcia (BP $\geq 140 / 90 \mathrm{mmHg}$ with proteinuria+1 on dipstick method)

- Coagulopathy (INR>2) or active thromboembolic state (on medical record)

- Hypersensitivity to tranexamic acid (history)

Data Collection Procedure: After taking Hospital ethical committee approval, 200 women who fulfilled inclusion criteria were enrolled from indoor of Obstetrics \& Gynecology Department, Allied hospital Faisalabad. Informed consent was taken. Demographic details (name, age, gestational age, parity) were also obtained. All the patients were randomly divided into two groups by using random number table. Group A patients received tranexamic acid $(1 \mathrm{gm} / 10 \mathrm{ml}$ TA diluted with $20 \mathrm{ml}$ of $5 \%$ glucose) and group B patients not received tranexamic acid (placebo). Trial drug was slowly administered intravenously over a five-minute period at least 10 minutes prior to skin incision. After delivery, both groups received a $5 \mathrm{IU}$ intravenous bolus of pre-prepared oxytocin and then $30 \mathrm{IU}$ oxytocin in $500 \mathrm{ml}$ lactated Ringer's solution was infused at a rate of $125 \mathrm{ml} / \mathrm{h}$. Blood loss was measured from delivery of placenta till completion of caesarean section (i.e. closure of uterus and skin). Blood loss was noted by measuring the total blood collected in kidney tray of $10^{\prime \prime}$ in size during delivery of placenta till completion of caesarean section. All this information was recorded through study proforma.

Statistical Analysis: All the data was entered and analyzed by using SPSS V-21. Mean and standard deviation was calculated for all quantitative variables like age, gestational age and blood loss. Parity was presented as frequency. Independent sample ttest was used to compare mean blood loss between two groups. $P$-value $\leq 0.05$ was taken as significant.

\section{RESULTS}

Total 200 patients were evaluated. The overall mean age of the patients was $29.90 \pm 6.06$ years. However particularly mean age of the patients of TXA group was $29.53 \pm 5.81$ years and in placebo group was $30.27 \pm 6.32$ years. Average gestational age was 38.94 \pm 0.814 weeks were noted in TXA group 39.02 \pm 0.864 weeks was in placebo group. Parity 1-3 was commonest in groups as $74.0 \%$ in TXA group and $77.0 \%$ in control group, followed by $8.0 \%$ women were nulliparous in TXA group and $12.0 \%$ were in control group, while in TXA group $18.0 \%$ presented with parity $>3$ and $11.0 \%$ in control group, parity was statistically insignificant according to both groups $(p=0.078)$. Table 1

Table 1: Demographic statistics of the patients $n=200$

\begin{tabular}{|c|c|c|c|c|}
\hline \multicolumn{2}{|c|}{ Variables } & \multicolumn{2}{c|}{ Study Groups } & \multirow{2}{p}{ - } \\
\cline { 3 - 4 } value
\end{tabular}

Mean blood loss in TXA group was $333.74 \pm 40.92 \mathrm{ml}$ which is significantly lower in contrast to control group $440.80 \pm 93.064$ $\mathrm{ml},(\mathrm{p}=0.001)$. Figure 1

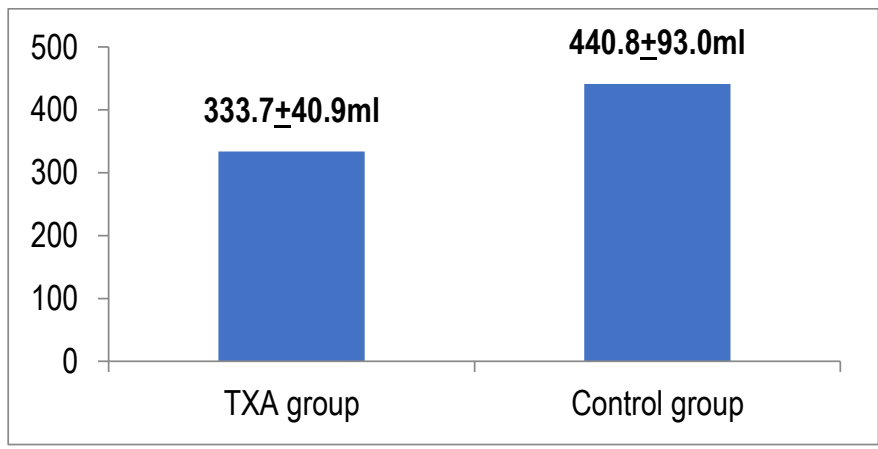

Figure 1: Comparison of average blood loss in both groups $\mathrm{n}=200$

Independent $t$ test $=-10.531 \quad p$-value $=0.001^{\text {* }}$ 
In TXA group patients having age $\leq 30$ years, the mean of blood loss in TXA group was $329.19 \pm 42.62 \mathrm{ml}$, which was significantly lower as compared to placebo group $439.12 \pm 92.99 \mathrm{ml}$ $(p=0.001)$. Similarly, in patients having age $>30$ years, the average blood loss significantly decreased in contrast to controls $(p=0.001)$. However, average of blood loss was significantly less in TXA group as compared to control groups, when assessed according to gestational age and parity $p$-values were quite significant. Table 2

Table 2: Comparison of blood loss with study groups stratified by age

\begin{tabular}{|c|c|c|c|c|}
\hline \multirow{2}{*}{ Age } & \multirow{2}{*}{ Study Groups } & \multicolumn{2}{|c|}{ Blood Loss } & \multirow{2}{*}{ p-value } \\
\hline & & Mean & SD & \\
\hline \multirow{2}{*}{$\leq 30$ years } & TXA & 329.19 & 42.62 & \multirow{2}{*}{$0.000^{*}$} \\
\hline & Placebo & 439.12 & 92.99 & \\
\hline \multirow{2}{*}{$>30$ years } & TXA & 339.77 & 38.21 & \multirow{2}{*}{$0.000^{*}$} \\
\hline & Placebo & 442.63 & 94.08 & \\
\hline \multicolumn{5}{|c|}{ Gestational age } \\
\hline \multirow{2}{*}{38 weeks } & TXA & 336.50 & 40.63 & \multirow{2}{*}{$0.000^{*}$} \\
\hline & Placebo & 471.50 & 93.28 & \\
\hline \multirow{2}{*}{39 weeks } & TXA & 333.47 & 44.47 & \multirow{2}{*}{$0.000^{*}$} \\
\hline & Placebo & 415.00 & 78.99 & \\
\hline \multirow{2}{*}{40 weeks } & TXA & 330.73 & 38.14 & \multirow{2}{*}{$0.000^{*}$} \\
\hline & Placebo & 429.37 & 95.95 & \\
\hline \multicolumn{5}{|l|}{ Parity } \\
\hline \multirow{2}{*}{ Primi } & TXA & 327.27 & 35.93 & \multirow{2}{*}{$0.000^{*}$} \\
\hline & Placebo & 432.73 & 104.40 & \\
\hline \multirow{2}{*}{ Multi } & TXA & 336.51 & 42.82 & \multirow{2}{*}{$0.000^{*}$} \\
\hline & Placebo & 445.54 & 86.25 & \\
\hline
\end{tabular}

\section{DISCUSSION}

This study was conducted at Obstetrics \& Gynecology Department, Allied hospital Faisalabad to compare mean blood loss with TXA versus placebo given before delivery in females undergoing elective caesarean section.

Obstetric hemorrhage remains one of the major determinants of maternal death in both developed and developing countries. $\mathrm{PPH}$ is a common and potentially life-threatening complication of labour. Because of its weight as a leading cause of maternal mortality and morbidity, obstetric hemorrhage must be investigated for national guideline development. ${ }^{9}$ Antifibrinolytic drugs, namely TXA have been recognized to decrease blood loss and transfusion needs in various elective surgeries. ${ }^{10}$ In this study the overall mean blood loss value of the patients was $387.27 \pm 89.56 \mathrm{ml}$. In our study the mean value of blood loss in TXA group was $333.74 \pm 40.92 \mathrm{ml}$ and its mean value in placebo group was $440.80 \pm 93.064 \mathrm{ml}$. Statistically highly significant difference was found between the study groups with blood loss of the patients. i.e. $p$-value $=0.000$. Some of the studies are discussed below showing the results in favor of our study as.

Shahid et al, found that TXA significantly reduced the quantity of blood loss from placental delivery to the end of LSCS and it also reduced the quantity of blood loss from the end of LSCS to 2 hours post-partum. Shahid et al, concluded that TXA can be used safely and effectively in women undergoing LSCS to reduce intra-operative blood loss. ${ }^{3}$

One more study by Leila Sekhavat et al concluded that TXA statistically reduces blood loss from end to 2 hours after CS and its use was not associated with any side effects or complications. They showed that the TXA significantly reduced the blood loss from the end of CS to 2 hours postpartum; 28.02 $\pm 5.53 \mathrm{ml}$ in the tranexamic group versus $37.12 \pm 8.97 \mathrm{ml}$ in the control group $(p=0.000) .{ }^{11}$

Abdel Aleem and colleagues; concluded that the pre-operative use of TXA is associated with reduced blood loss during and after elective CS. ${ }^{12}$ They enrolled seven hundred and forty women ( 373 in study group and 367 in control group). Mean total blood loss was 241.6 (SE 6.77) $\mathrm{ml}$ in the TXA group versus 510 (SE 7.72) $\mathrm{ml}$ in the control group.

A study by Amr H. Yehia et al ${ }^{13}$ resulted that total blood loss from placental delivery till end of caesarean section was significantly less in TXA group compared to control (369.5 \pm 198.0 versus $606.8 \pm 193.0 \mathrm{ml}$; respectively). Also calculated vaginal bleeding during first 6 hours post-operative was significantly less in TXA group compared to control (85.0 \pm 30.7 $\mathrm{ml}$ versus $130.8 \pm 49.3 \mathrm{ml}$, respectively). The incidence of PPH was significantly less in TXA group compared to control $31.1 \%$ versus $63.2 \%$; respectively.

Six hundred and sixty women (660) women who underwent elective CS were included in Gungorduk and colleagues study to determine the efficacy and safety of TXA in reducing blood loss during elective CS. Gungorduk and colleagues found that TXA significantly reduced bleeding during CS and reduced the need for additional uterotonic agents. ${ }^{2}$

Two hundred and twenty-three (223) women (101 study group \& 122 control) were included in Sentürk \& colleagues doubleblind trial. They found that TXA reduced intra-operative and post-operative blood loss and they did not observe any complications caused by TXA such as venous thromboembolism, gastrointestinal problems and hypersensitivity. ${ }^{14}$

TXA is an antifibrinolytic agent, and a recent systematic review of antifibrinolytic agents in PPH reported a reduction in blood loss of $92 \mathrm{ml}(\mathrm{Cl} 76$ to $109 \mathrm{ml}) .{ }^{15}$

But on the other hand, in one trial, the mean blood loss was $336.7 \pm 151.2 \mathrm{ml}$ in the TXA group than $368.5 \pm 156.4 \mathrm{ml}$ in the control group. However, the amount of blood loss in the period from placental delivery to the end of CS did not differ between the TXA and control groups $(p=0.17){ }^{8}$ 


\section{CONCLUSION}

It has been proved in our study that the TXA is useful and effective drug to control the mean blood loss before delivery in females undergoing elective caesarean section as compared to placebo group.

\section{LIMITATIONS}

As this study is conducted only on elective LSCS so effect of drugs on emergency and complicated LSCS with placenta accreta spectrum are to be studied.

\section{SUGGESTIONS / RECOMMENDATIONS}

As TXA is very effective in prevention of primary PPH in low risk LSCS and this drug is also cost effective and with less side effect profile. So, I will suggest Government authorities to add this drug in EMOC (Emergency Obstetric Care) at all BHU's.

\section{CONFLICT OF INTEREST / DISCLOSURE}

There is no conflict of interest in this study.

\section{ACKNOWLEDGEMENTS}

I would like to thank all staff nurses for their help in measuring blood loss for data collection.

\section{REFERENCES}

1. Muñoz M, Stensballe J, Ducloy-Bouthors AS, Bonnet MP, De Robertis E, Fornet I, et al. Patient blood management in obstetrics: prevention and treatment of postpartum haemorrhage. A NATA consensus statement. Blood Transfus. 2019;17(2):11236.

2. Gungorduk K, Yıldırım G, Asıcıoğlu O, Gungorduk OC, Sudolmus $S$, Ark C. Efficacy of intravenous tranexamic acid in reducing blood loss after elective cesarean section: a prospective, randomized, double-blind, placebo-controlled study. Am J Perinatol. 2011;28(3):233-40.

3. Shahid A, Khan A. Tranexamic acid in decreasing blood loss during and after caesarean section. J Coll Physicians Surg Pak. 2013;23(7):459-62.

4. Pakniat $H$, Khezri MB. The Effect of Combined OxytocinMisoprostol Versus Oxytocin and Misoprostol Alone in Reducing Blood Loss at Cesarean Delivery: A Prospective Randomized Double-Blind Study. J Obstet Gynaecol India. 2015;65(6):376-81.

5. Levy JH, Koster A, Quinones QJ, Milling TJ, Key NS. Antifibrinolytic Therapy and Perioperative Considerations. Anesthesiology. 2018;128(3):657-70.

6. Bofill Rodriguez M, Lethaby A, Low C, Cameron IT. Cyclical progestogens for heavy menstrual bleeding. Cochrane Database Syst Rev. 2019;8(8):CD001016.

7. Masuzawa Y, Kataoka Y, Fujii K, Inoue S. Prophylactic management of postpartum haemorrhage in the third stage of labour: an overview of systematic reviews. Syst Rev. 2018;7(1):156.

8. $\mathrm{Xu} \mathrm{J,} \mathrm{Gao} \mathrm{W,} \mathrm{Ju} \mathrm{Y.} \mathrm{Tranexamic} \mathrm{acid} \mathrm{for} \mathrm{the} \mathrm{prevention} \mathrm{of}$ postpartum hemorrhage after cesarean section: a double-blind randomization trial. Arch Gynecol Obstet. 2013;287(3):463-8.

9. Brace $V$, Kernaghan D, Penney $G$. Learning from adverse clinical outcomes: major obstetric haemorrhage in Scotland, 2003-05. BJOG: An Int J Obstet \& Gynaecol. 2007;114(11):1388-96.
10. Henry DA, Carless PA, Moxey AJ, O'Connell D, Stokes BJ, Fergusson DA, Ker K. Anti-fibrinolytic use for minimising perioperative allogeneic blood transfusion. Cochrane Database Syst Rev. 2011;(1):CD001886.

11. Sekhavat $L$, Tabatabaii A, Dalili M, Farajkhoda T, Tafti AD. Efficacy of tranexamic acid in reducing blood loss after cesarean section. J Matern Fetal Neonatal Med. 2009;22(1):72-5.

12. Abdel-Aleem $\mathrm{H}$, Alhusaini TK, Abdel-Aleem MA, Menoufy M, Gülmezoglu AM. Effectiveness of tranexamic acid on blood loss in patients undergoing elective cesarean section: randomized clinical trial. J Matern Fetal Neonatal Med. 2013;26(17):1705-9.

13. Yehia $\mathrm{AH}$, Koleib MH, Abdelazim IA, Atik A. Tranexamic acid reduces blood loss during and after cesarean section: $A$ double blinded, randomized, controlled trial. Asian Pacific J Reprod. 2014;3(1):53-6.

14. Sentürk MB, Cakmak Y, Yildiz G, Yildiz P. Tranexamic acid for cesarean section: a double-blind, placebo-controlled, randomized clinical trial. Arch Gynecol Obstet. 2013;287(4):6415.

15. Shakur H, Roberts I, Edwards P, Elbourne D, Alfirevic Z, Ronsmans $\mathrm{C}$. The effect of tranexamic acid on the risk of death and hysterectomy in women with post-partum haemorrhage: statistical analysis plan for the WOMAN trial. Trials. 2016;17(1):249.

\section{AUTHORSHIP CONTRIBUTION}

\begin{tabular}{|l|l|}
\hline $\begin{array}{l}\text { Dr. Sadaf Naeem } \\
\text { Senior Registrar, Department of } \\
\text { Gynecology \& Obstetrics, Allied Hospital, } \\
\text { Faisalabad Pakistan }\end{array}$ & $\begin{array}{l}\text { Manuscript Writing, Study } \\
\text { Design, Data Analysis, } \\
\text { Conceptualized the Idea }\end{array}$ \\
\hline $\begin{array}{l}\text { Dr. Memona Shaukat } \\
\text { Consultant Gynecologist } \\
\text { Faisalabad Pakistan }\end{array}$ & Data Collection \\
\hline $\begin{array}{l}\text { Dr. Ammara Niaz } \\
\text { Assistant Professor of Gynecology \& } \\
\text { Obstetrics, Faisalabad Medical University, } \\
\text { Faisalabad Pakistan }\end{array}$ & $\begin{array}{l}\text { Manuscript Writing, Data } \\
\text { Analysis, References } \\
\text { Collection }\end{array}$ \\
\hline $\begin{array}{l}\text { Dr. Tasnim Tahira } \\
\text { Professor of Gynecology \& Obstetrics, } \\
\text { Faisalabad Medical University, Faisalabad } \\
\text { Pakistan }\end{array}$ & $\begin{array}{l}\text { Critical Review of the } \\
\text { Article }\end{array}$ \\
\hline $\begin{array}{l}\text { Dr. Amna Batool } \\
\text { Senior Registrar of Gynecology \& } \\
\text { Obstetrics, Allied Hospital, Faisalabad } \\
\text { Pakistan }\end{array}$ & Data Collection \\
\hline $\begin{array}{l}\text { Dr. Sehrish Maqsood } \\
\text { Senior Registrar of Gynecology \& } \\
\text { Obstetrics, Allied Hospital, Faisalabad } \\
\text { Pakistan }\end{array}$ & \\
\hline
\end{tabular}

